Archived version from NCDOCKS Institutional Repository http://libres.uncg.edu/ir/asu/

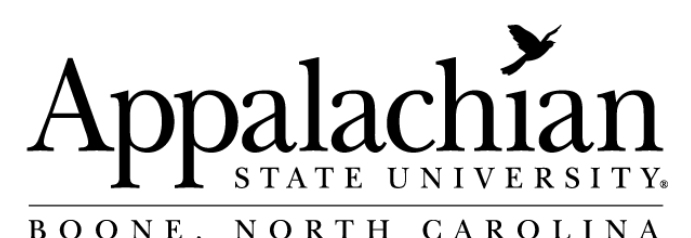

\title{
Carbon Accounting: Issues of Scale
}

By: Gregg Marland,Tammy Kowalczyk, and Eric Marland

Marland, G., T. Kowalczyk, and E. Marland, 2015. Carbon accounting: issues of scale. Journal of Industrial Ecology ISSN: $1088-1980$ 


\section{Carbon Accounting: Issues of Scale}

Gregg Marland,

Tammy Kowalczyk,

Eric Marland

Accounting for carbon dioxide ( $\mathrm{CO} 2$ ) emissions to the atmosphere is being widely implemented at many spatial, temporal, and organizational scales-country or city, year or day,

"Even if the scale issues related to attribution and mitigation could be resolved and we could determine who is responsible for emissions within some spatial and temporal boundaries, the questions of appropriate measurement may still remain."

Financial accounting is typically at the level of an entity, defined in terms of ownership, management control, or responsibility. Carbon accounting raises similar accounting concerns, but has different issues of scale. Carbon accounting is necessary to address questions of attribution, mitigation, impact, adaptation, and of monitoring and verification. Yet some scales of accounting raise important questions. For example, our recent work on emissions from large point sources notes that power plants and petroleum refineries in the United States supply goods and services to a widely dispersed customer base while discharging $\mathrm{CO} 2$ at one point in one county and state. In the same context, it has been estimated that 33\% of emissions from China in 2005 were associated with exports to mostly richer, developed countries (Weber and Matthews 2008). With respect to temporal scale, harvesting trees to burn for energy while replanting trees may suggest large net emissions in an annual time frame, but no net emissions in a 60-year window. In an increasingly global business economy the production and sale of any good will probably affect the carbon emissions of multiple locations and times around the world. So at what spatial, temporal, and organizational scales do we then address the attribution, mitigation, impact, and adaptation of $\mathrm{CO} 2$ emissions? The complexity of carbon stocks and flows and the variety of societal and decision-maker needs suggest that accounting proceed on multiple scales. However, the utility of different scales for accounting and accommodating accounts across scales need careful thought.

\section{Attribution and Mitigation}

If our intent is to promote mitigation or reduction of $\mathrm{CO} 2$ emissions, we have ultimately to account for responsibility. This might be done at an "entity" level, for example, personal, product, facility, corporate, state, or national scale-or at some nested set of these scales. Responsibility might be assumed at the point of emissions, final consumption, or some point in between. Emissions from electric power generation, for example, could be the responsibility of the power producer, the factory that purchases the power, or the ultimate consumer. We recognize that employment opportunities and economic 
benefits fall to both the power producer and the factory even as the final consumer may be seen as the driver. And these three parties might reside in different countries so that this choice on responsibility affects national as well as corporate accounts. Does responsibility lie with the country where emissions are discharged (as in the Kyoto Protocol) or in the country of final consumption (as is often suggested)? Perhaps responsibility tracks back to the primary producer (e.g., the coal mining company), as implied by Heede (2014).

Accounting can be done at any, or all, of these scales but preferences expressed in public policy will determine how potential decision makers are impacted and at what scale decisions will be made. And there are scales at which it is pragmatically easier to exert pressure or educate-to influence decision makers (i.e., lightbulb manufacturers rather than lightbulb purchasers). And we still confront the challenge of incomplete participation-are objectives achieved if some, but not all, entities adopt mitigation measures? With partial participation or participation with different parameters it is possible to encounter economic leakage, multiple claims on the same carbon, or attempts to game the system.

Because $\mathrm{CO} 2$ has a long lifetime in the atmosphere and because its impact on climate depends on the atmospheric concentration and not on the level of current emissions, time too is a scale issue in carbon accounting. Responsibility might be based on current emissions, contributions to the total atmospheric increase, the full sum of historic emissions, emissions since the danger of emissions was first acknowledged, or on some other time-dependent interval (den Elzen et al. 2013). We could also consider current actions that obligate future emissions (e.g., production that requires future waste processing or capital investment that commits future use of fossil fuels). Also, are emissions of similar value regardless of the time (past, present, or future) that they are discharged or is some discounting appropriate1 (e.g., Richards 1997)? If accounting is over short time intervals, the time value of emissions may be unimportant but in forest management or in a life cycle assessment (LCA), where waste disposal or other end-of-life issues are important, the time value of emissions could be a major consideration.

Even if the scale issues related to attribution and mitigation could be resolved and we could determine who is responsible for emissions within some spatial and temporal boundaries, the questions of appropriate measurement may still remain. As in traditional financial accounting, implementing the conceptual notion of appropriate measurement is hindered by the inability to model the metrics that provide meaningful information to decision makers. Fine-scale estimates of emissions based on proxies, for example, may tell us more about the proxies than about the real distribution of emissions. The issue of scale must consider the feasibility of measurement.

\section{Impact and Adaptation}

Issues of scale and accounting boundaries also inhabit the realm of impact and adaptation. Emissions, at least through effects on the atmosphere, will have the same impact on climate regardless of where they originate. Many human impacts of carbon emissions or of carbon cycle management, however, are at less than the global scale. In a recent column in this Journal (Marland et al. 2013), for example, we 
argued that facilities using biomass fuels are logically connected with the landscapes from which the fuels are harvested and could be connected in accounting. Many agricultural practices and changes in land use affect the global atmospheric $\mathrm{CO} 2$ but they also affect the carbon dynamics of specific, local landscapes. Through physical and economic linkages, activities that impact carbon flows can have ecological impacts in distant places and times. Protecting forests in one place, for example, could accelerate deforestation elsewhere. We consider wood to be a sustainable fuel, but does sustainability have a spatial and temporal scale? Does it matter if we are depleting forests locally so long as they are "sustained" at the national level? Carbon flows may be sustainable at the national level but ecosystem services and noncarbon benefits may be important at much finer scales. Similarly, does ensuring the sustainability of wood fuel impact the sustainability of other forms of natural or human capital, or of disrupted or displaced ecosystems? There is a similar problem in traditional accounting systems, where valuation for a financial performance metric (e.g., net income) does not appropriately include nonfinancial costs (e.g., environmental damage from waste).

It is clear that a separation in time alters the equivalence of an emission and an offset; the more closely the two occur in time, the more closely they can be considered to balance each other. The same might be said spatially as well; the closer the emissions and the offset are in space, the more closely they balance each other. How then does physical separation alter the effectiveness or value of an offset?

In order to accommodate annual variability in the global carbon cycle, yearly accounting seems an appropriate temporal scale for many purposes, but for applications such as forest management and LCA it raises the question of the time value of emissions. For forest management we may avoid some time issues if we can integrate over space rather than over time (a landscape, rather than a forest stand). This might reduce the uncertainty of future decision pathways. Similarly, for life insurance and many social programs we find it useful to pay benefits from current monetary inflows rather than from accumulated investments to better account for temporal-scale issues.

\section{Political, Corporate, and Personal Accounting}

Accounting boundaries for political entities, physical areas, corporations, or individuals may be at very different scales. The question may often focus on what can be controlled, which in turn affects what can be measured. An individual can control purchasing choices; a corporation can control production efficiency and energy sources; and a country can control resource consumption, process emissions, and international trade. It is a challenge of accounting, attribution, incorporating uncertainty, and education when a consumer might be considered responsible for very large net $\mathrm{CO} 2$ emissions despite having no direct emissions and a manufacturer might trade or pay taxes on emissions that are totally different from those attributed to its products by LCA.

Note that participation in mitigation strategies does not occur simultaneously by all. Already, some parties have begun implementing practices while others are looking to begin. What are the effects of a 
stepped implementation? As an early adopter begins to buy green power, the green power is no longer available to a second party (including the seller). Does this make it more difficult for the second party to participate? Does the second party bear the marginal cost or do the parties share the average cost? The accounting boundaries become very important.

\section{Monitoring and Verification}

Monitoring and verification depend, ultimately, on independent measurements. Does income balance outgo or can the flows be measured independently by different methods or different parties? It turns out that because of the role of carbon accumulation in the atmosphere and carbon exchange with the oceans the only scale at which we can balance the atmospheric carbon account is global. Full carbon accounting globally is required to verify a global balance. And yet space-based measurements have been suggested to monitor and verify national, city, or corporate reports. Matching data from satellite passes with ground-based flux measures suggests the need for ground-based measurements at spatial and temporal scales comparable to satellite capabilities and atmospheric modeling possibilities.

\section{Conclusions}

We recognize that there are physical, political, market-enabling, financial, and social/environmental reasons for carbon accounting (Ascui and Lovell 2011) and that these have widely varying needs for both the spatial, temporal, and organizational scales of carbon accounting and for the accuracy of this accounting. We have to know what data are material (how the data will be used) and what data can be collected. We have social preferences that will weigh key issues such as the scale at which sustainability will be evaluated and time preference expressed. It may be relatively easy to do an inventory of emissions; it is not so straightforward to do a useful accounting, one that provides relevant information for decision making. The recently announced U.S. program to reduce net $\mathrm{CO} 2$ emissions from electric generating units2, for example, leaves much of the implementation decisions to the states. With so much involvement of interstate trade, travel, and entities, there will be many issues of scale, including the scale of sustainability. Ultimately though, we should keep in mind that the objective is to reduce global emissions.

Notes

1. See, for example, the U.S. government's effort to calculate a social cost of carbon: www.whitehouse.gov/sites/default/files/omb/inforeg/social_cost_of_carbon_for_ria_2013_up date.pdf.

2. See www2.epa.gov/sites/production/files/2014-05/documents/20140602proposalcleanpowerplan.pdf.

Biographies 
1. Gregg Marland is a research professor in the Research Institute for Environment, Energy, and Economics,

2. Tammy Kowalczyk is an associate professor of accounting in the Walker College of Business, and

3. Eric Marland is a professor in the Department of Mathematical Sciences, all at Appalachian State University in Boone, NC, USA.

\section{References}

1. Ascui, F. and H. Lovell. 2011. As frames collide: Making sense of carbon accounting. Accounting, Auditing, and Accountability Journal 24(8): 978-999.

2. den Elzen, M. G. J., J. G. J. Olivier, N. Höhne, and G. Janssens-Maenhout. 2013. Countries' contributions to climate change: Effect of accounting for all greenhouse gases, recent trends, basic needs and technological progress. Climatic Change 121(2): 397-412.

3. Heede, R. 2014. Tracing anthropogenic carbon dioxide and methane emissions to fossil fuel and cement producers, 1854-2010. Climatic Change 122(1-2): 229-241.

4. Marland, G., T. Buchholz, and T. Kowalczyk. 2013. Accounting for carbon dioxide emissions: The context and stakeholders matter. Journal of Industrial Ecology 17(3): 340-342.

5. Richards, K. 1997. The time value of carbon in bottom-up studies. Critical Reviews in Environmental Science and Technology 27(Special Issue):S279-S292.

6. Weber C. L. and S. H. Matthews. (2008). Quantifying the global and distributional aspects of American household carbon footprint. Ecological Economics 6(6): 379-391. 